\title{
Ecogeografia de populações de erva-baleeira (Varronia curassavica) no Norte e Vale do Jequitinhonha em Minas Gerais
}

\author{
Ecogeography populations of Cordia (Varronia curassavica) in North and Jequitinhonha Valley in \\ Minas Gerais, Brazil
}

\author{
Aretusa Daniela Resende Mendes ${ }^{I^{*}}$ Cristina Rodrigues Nascimento $^{\mathrm{II}}$ Túlio Barroso Queiroz \\ Vitor Batista Pinto ${ }^{\text {III }}$ Ernane Ronie Martins ${ }^{I}$
}

\section{RESUMO}

O objetivo deste estudo foi avaliar as condições ecogeográficas e edafoclimáticas dos ambientes de ocorrência da erva-baleeira (Varronia curassavica) nas mesorregiões Norte e Vale do Jequitinhonha de Minas Gerais. O estudo foi efetuado em 15 sitios de ocorrência dessa espécie, localizados em 14 municipios sob o bioma Cerrado e ocorreu nos tipos de vegetação Cerrado, Caatinga, restinga e floresta. Os sitios estão localizados predominantemente entre 495 e $895 \mathrm{~m}$ de altitude, e as plantas localizam-se sempre na parte inferior da topossequência. A precipitação média anual variou de $<1.000 \mathrm{~mm}$ a $1.500 \mathrm{~mm}$ e a temperatura média anual variou de $<19$ a $24^{\circ} \mathrm{C}$. A espécie tolera solos fortemente ácidos e com alta saturação de alumínio, ocorrendo em diferentes níveis de fertilidade e classes de solo. Nas mesorregiões Norte e Vale Jequitinhonha de Minas Gerais, a erva-baleeira não apresentou condições ecogeográficas e edafoclimáticas especificas para a sua ocorrência.

Palavras-chave: caracterização ambiental, edafoclimáticas, planta medicinal, dispersão, Cerrado, Boraginacea.

\section{ABSTRACT}

The objective of this study was to evaluate the ecogeographic and edaphoclimatic conditions of the environments of occurrence of Cordia (Varronia curassavica) at the mesoregions Northern and Jequitinhonha Valley in Minas Gerais. The study was conducted in 15 places of occurrence of this species, located in 14 municipalities under the Cerrado biome and occurred in the Cerrado, Caatinga, marsh and, forest vegetation types. The places are located predominantly between 495 and $895 \mathrm{~m}$ of altitude, and the plants are located always at the bottom of the top sequence. The annual average rainfall ranged from $<1,000 \mathrm{~mm}$ to $1,500 \mathrm{~mm}$ and the annual average temperature ranged from $<19$ to $24^{\circ} \mathrm{C}$. The species tolerates acid soils with high aluminum saturation, occurring at different fertility levels and soil types. In the mesoregions Northern and Jequitinhonha Valley in Minas Gerais the Cordia showed no ecogeographic and climatic specific conditions for its occurrence.

Key words: environmental characterization, edaphoclimatic, medicinal plant, dispersion, Cerrado, Boraginacea.

\section{INTRODUÇÃO}

A produção de plantas medicinais vem se destacando no agronegócio brasileiro, devido ao crescimento do consumo de medicamentos a base de plantas no Brasil (LOURENZANI et al., 2004). No entanto, a cadeia produtiva de plantas medicinais, de cultivo e de extrativismo, não está organizada. Das 400 plantas medicinais comercializadas no Brasil, $75 \%$ são de origem extrativa, coletadas diretamente no ambiente de ocorrência natural, sem qualquer manejo, o que gera grande pressão no ecossistema, causando problemas na sustentabilidade e risco de extinção (BARATA, 2005).

Entre as plantas medicinais comercializados no Brasil, Varronia curassavica (sinonímia Cordia verbenacea - Boraginaceae), conhecida popularmente como "erva-baleeira" (MILLER \& GOTTSCHLING, 2007), mostra-se promissora por estar sendo utilizada como insumo de um fitoterápico produzido e comercializado no

'Laboratório de Plantas Medicinais, Universidade Federal de Minas Gerais (UFMG), Campus Montes Claros, 39404-547, Montes Claros, MG, Brasil. E-mail: are.dani@hotmail.com.*Autor para correspondência.

"UFMG, Montes Claros, MG, Brasil.

"'Universidade Federal de Viçosa (UFV), Viçosa, MG, Brasil. 
Brasil. Os marcadores químicos desse fitoterápico são dois sesquiterpenos, o alfa-humuleno e o transcariofileno, que estão presentes no óleo essencial das folhas da erva-baleeira, os quais possuem ação antiinflamatória (FERNANDES et al., 2007; MEDEIROS et al., 2007).

Devido às propriedades terapêuticas da erva-baleeira, existe grande interesse na ampliação de estudos sobre a planta, principalmente estudos voltados para a seleção de genótipos interessantes quanto aos seus aspectos agronômicos e a sua composição química (VAZ et al., 2006).

Nas mesorregiões Norte e Vale do Jequitinhonha de Minas Gerais, existem áreas de Cerrado, Caatinga e Mata Atlântica em que há a ocorrência natural da erva-baleeira. Nessas áreas, os processos de intervenção humana e de extrativismo indiscriminado exigem uma rápida ação para conservação das espécies medicinais in situ ou ex situ, que são complementares. No entanto, como auxílio à conservação ex situ e à domesticação da espécie, existe a necessidade de se estudar e conhecer o ambiente de ocorrência. Assim, o objetivo deste trabalho foi investigar as condições ecogeográficas e edafoclimáticas dos ambientes de ocorrência da erva-baleeira no Norte e Vale do Jequitinhonha, em Minas Gerais.

\section{MATERIAL E MÉTODOS}

O trabalho foi realizado de dezembro de 2010 a dezembro de 2012, nas mesorregiões Norte e Vale Jequitinhonha do estado de Minas Gerais, selecionando-se quinze sítios de ocorrência natural da erva-baleeira. Os sítios foram marcados utilizando receptor GPS (Global Position System) Garmin Oregon 550, e determinando-se suas coordenadas geográficas (latitude, longitude e altitude). A partir dos dados da posição geográfica coletados nos sítios de ocorrência (latitude, longitude e altitude), efetuouse a confecção da carta com os pontos ocorrência da erva-baleeira nas mesorregiões Norte e Vale Jequitinhonha de Minas Gerais.

A carta foi confeccionada com base em arquivos vetoriais disponibilizados pelo IBGE (2012). Os dados espaciais foram processados no SPRING (Sistema de Processamento de Imagens Geográficas), versão 5.1.8. Na sequência, para caracterizar os sítios de ocorrência de erva-baleeira, nas mesorregiões do Norte e Vale do Jequitinhonha de Minas Gerais, identificou o bioma, o tipo de vegetação, a precipitação média anual e a temperatura média anual, utilizando cartas temáticas disponibilizadas pelo IBGE (2012).
Para as análises das propriedades químicas do solo, foram realizadas amostragens em cada sítio de ocorrência, na camada $0-20 \mathrm{~cm}$ de profundidade, com o auxílio de trado holandês, sendo realizadas cinco tradagens por sítio para formar cada amostra composta. As análises químicas foram realizadas no Laboratório de Solos do Instituto de Ciências Agrárias da Universidade Federal de Minas Gerais, Montes Claros, Minas Gerais. As determinações analíticas foram obtidas segundo as marchas de extração e determinação propostas pela EMBRAPA (1997) e estão de acordo com os métodos analíticos recomendados pela CFSEMG (1999). Os solos foram classificados conforme o Sistema Brasileiro de Classificação de Solos (SANTOS et al., 2006).

Os resultados das análises das propriedades químicas do solo foram submetidos à técnica multivariada por meio da análise de componentes principais, a partir da qual foi reduzido o conjunto de dados em combinações lineares, gerando escores em torno de $80 \%$ da variação total, conforme recomendado por CRUZ \& REGAZZI (1994). Isso permitiu identificar as propriedades químicas mais relevantes na discriminação dos diferentes sítios de ocorrência. A análise de componentes principais foi realizada a partir da matriz de correlação, selecionando as propriedades que apresentaram correlações de Pearson maiores que 0,5 entre si. A seguir, os dados foram submetidos à Análise de Função Discriminante, que busca descobrir se é possível separar dois ou mais grupos com base nas medidas. Na execução dessas análises, foi utilizado o software GENES (CRUZ, 2006).

\section{RESULTADOS E DISCUSSÃO}

Os sítios de ocorrência da erva-baleeira estão distribuídos em 14 municípios das mesorregiões Norte e Vale Jequitinhonha do estado de Minas Gerais, sendo eles: Angelândia, Botumirim, Coração de Jesus, Cristália, Engenheiro Navarro, Gouveia, Grão Mongol, Itacambira, Juramento, Montes Claros, Pintópolis, Rio Pardo de Minas, São Francisco e Turmalina (Figura 1). Os municípios estão localizados entre as coordenadas geográficas $15^{\circ} 30^{\prime} 55,0^{\prime \prime}$ e

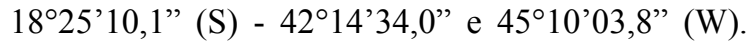
Segundo MONTANARI JUNIOR (2011), a espécie ocorre espontaneamente em áreas litorâneas como restingas, sendo comum encontrá-la em regiões afastadas da costa, como o interior dos estados de São Paulo, Minas Gerais e Goiás. No presente trabalho, observou-se uma distribuição esparsa e casualmente efêmeras nas mesorregiões estudadas. 


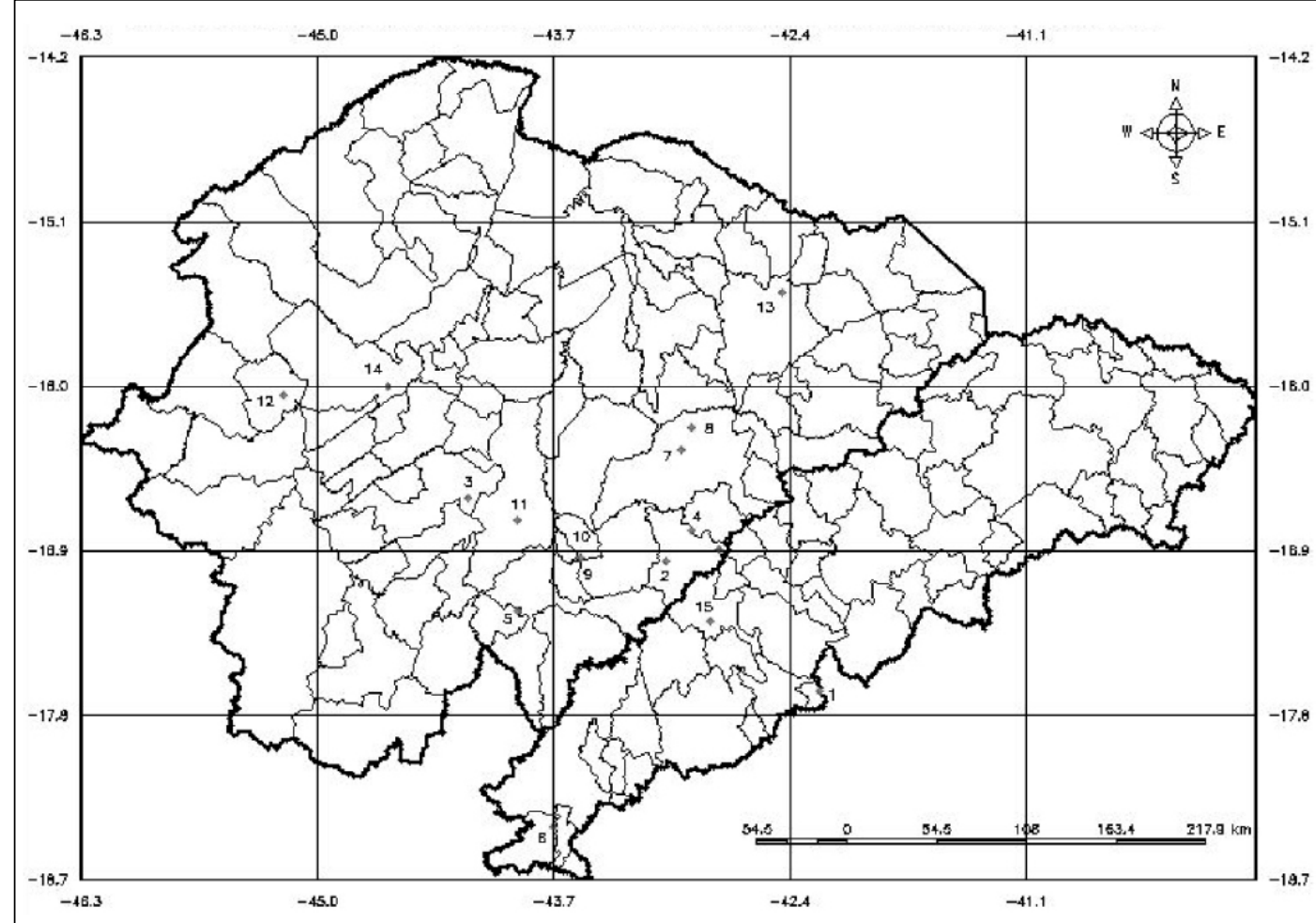

Identificação dos sítios de ocorrência dos números: 1 - Angelândia, 2 - Botumirim, 3 - Coração de Jesus, 4 - Cristália, 5 - Engenheiro Navarro, 6 - Gouveia, 7 - Grão Mongol, 8 - Grão Mongol (Assentamento Americana), 9 - Itacambira, 10 Juramento, 11 - Montes Claros, 12 - Pintópolis, 13 - Rio Pardo de Minas, 14 - São Francisco e 15 - Turmalina.

Figura 1 - Carta política das mesorregiões Norte e Vale Jequitinhonha de Minas Gerais, com pontos representando os 15 sítios de ocorrência da erva-baleeira (Varronia curassavica).

Fonte do mapa base: IBGE (2012).

As plantas de erva-baleeira estavam localizadas entre 495m (Pintópolis), a 1316m de altitude (Gouveia) (Tabela 1), não apresentando uma altitude específica, observando-se que as plantas se localizavam na parte mais baixa da topossequência desses sítios de ocorrência. O maior número de sítios de ocorrência foi observado nas altitudes entre 495 e 895m (Tabela 1). A erva-baleeira ocorre em altitudes que variam do nível do mar até altas altitudes, observando que a sua distribuição é generalizada (SÁNCHEZ, 1995).

No presente trabalho, dos 15 sítios de ocorrência, 13 encontram-se no bioma Cerrado e os municípios de Angelândia e Rio Pardo de Minas estão localizados em uma área de transição do bioma Cerrado e Mata Atlântica. O tipo de vegetação em que se encontram os sítios de ocorrência de Botumirim, Coração de Jesus, Cristália, Engenheiro Navarro, Itacambira, Juramento, Montes Claros, São Francisco, Turmalina e Rio Pardo de Minas foi Cerrado e Campo de Cerrado. Na vegetação do tipo Caatinga, encontraram os sítios de ocorrência do município de Grão Mogol e Pintópolis. O sítio do município de Angelândia apresenta Mata Atlântica. Em Gouveia, a vegetação é do tipo campo rupestre de altitude. As plantas se desenvolviam de forma dispersa, em clareiras e ou beira de mata, independentemente do tipo do bioma e da vegetação.

Relatos anteriores da ocorrência da ervabaleeira em diferentes biomas e tipos de vegetação foram citados por diversos autores. RODAL \& NASCIMENTO (2002) encontraram a erva-baleeira na Caatinga de Pernambuco, habitando a floresta de altitude e as baixadas de vegetação xerófita. Outros trabalhos relatam a ocorrência de áreas de restinga (GANDOLFO \& HANAZAKI, 2011) e em campos rupestres (GASTAUER et al., 2012).

Os estudos com plantas de erva-baleeira de origem do Cerrado e dos tipos de vegetações encontrados nos sítios de ocorrência das mesorregiões Norte e Vale Jequitinhonha do estado de Minas Gerais são escassos e, possivelmente, essas plantas apresentam

Ciência Rural, v.45, n.3, mar, 2015. 
Tabela 1 - Caracterização dos 15 sítios de ocorrência da erva-baleeira (Varronia curassavica) nas mesorregiões Norte e Vale Jequitinhonha de Minas Gerais.

\begin{tabular}{|c|c|c|c|c|c|}
\hline № do sítio & Município & Altitude (m) & $\begin{array}{l}\text { Precipitação média anual } \\
(\mathrm{mm})\end{array}$ & $\begin{array}{l}\text { Temp. média anual } \\
\left({ }^{\circ} \mathrm{C}\right)\end{array}$ & Classe de solo \\
\hline 1 & Angelândia & 970 & $1200-1500$ & $21-22$ & LVAd \\
\hline 2 & Botumirim & 713 & $1000-1200$ & $21-22$ & RLd \\
\hline 3 & Coração de Jesus & 970 & $1000-1200$ & $22-24$ & LVe \\
\hline 4 & Cristália & 803 & $1000-1200$ & $22-24$ & PVd \\
\hline 5 & Engenheiro Navarro & 703 & $1000-1200$ & $22-24$ & LVAe \\
\hline 6 & Gouveia & 1316 & $1200-1500$ & $<19$ & RLe \\
\hline 7 & Grão Mongol & 843 & $1000-1200$ & $21-22$ & PVvd \\
\hline 8 & $\begin{array}{l}\text { Grão Mongol (Assent. } \\
\text { Americana) }\end{array}$ & 798 & $1000-1200$ & $21-22$ & RLe \\
\hline 9 & Itacambira & 863 & $1000-1200$ & $21-22$ & RLd \\
\hline 10 & Juramento & 963 & $1000-1200$ & $21-22$ & RLd \\
\hline 11 & Montes Claros & 639 & $1000-1200$ & $22-24$ & PVvd \\
\hline 12 & Pintópolis & 495 & $1000-1200$ & $22-24$ & CXve \\
\hline 13 & Rio Pardo de Minas & 842 & $<1000$ & $21-22$ & CXve \\
\hline 14 & São Francisco & 675 & $1000-1200$ & $22-24$ & PAe \\
\hline 15 & Turmalina & 573 & $1000-1200$ & $21-22$ & PVvd \\
\hline
\end{tabular}

PAe: Argissolo Amarelo Eutrófico; PVd: Argissolo Vermelho Distrófico; PVvd: Argissolo Vermelho Ta Distrófico; CXve: Cambissolo Háplico Ta Eutrófico; LVAd: Latossolo Vermelho-Amarelo Distrófico; LVAe: Latossolo Vermelho-Amarelo Eutrófico; LVe: Latossolo Vermelho Eutrófico; RLd: Neossolo Litólico Distrófico; RLe: Neossolo Litólico Eutrófico.

grande variabilidade genética. $\mathrm{O}$ conhecimento do potencial agronômico e químico dessas plantas se faz necessário para a incorporação de genótipos promissores no programa de melhoramento da espécie.

A precipitação média anual variou de $<1.000$ a $1.500 \mathrm{~mm}$ (Tabela 1). Nos sítios de ocorrência dos municípios de Angelândia e Gouveia, apresentou-se uma precipitação média anual de 1.200 a $1.500 \mathrm{~mm}$ e, no município de Rio Pardo de Minas, a precipitação média anual foi menor que $1.000 \mathrm{~mm}$ e os demais sítios de ocorrência ocorreram em locais com precipitação média anual entre 1.000 a $1.200 \mathrm{~mm}$. A precipitação que ocorreu no município de Rio Pardo de Minas é semelhante à observada por RODAL \& NASCIMENTO (2002), que foi de $900 \mathrm{~mm}$ na Caatinga de Pernambuco. No entanto, no trabalho realizado por GASTAUER et al. (2012), a erva-baleeira ocorreu em áreas com precipitação anual variando de $1450-1800 \mathrm{~mm}$.

A temperatura média anual para 14 sítios de ocorrência foi superior a $21^{\circ} \mathrm{C}$, sendo oito sítios de ocorrência sob a temperatura média anual de 21 a $22^{\circ} \mathrm{C}$ e seis sob a temperatura média anual de 22 a $24^{\circ} \mathrm{C}$ (Tabela 1). No município de Gouveia, observouse temperatura média anual menor que $19^{\circ} \mathrm{C}$, o que ocorreu em função da altitude maior.

Com a análise dos componentes principais e a análise discriminante, avaliou-se a relação entre as propriedades químicas do solo dos 15 sítios de ocorrência da erva-baleeira, além de estabelecer agrupamentos de municípios com características similares. $\mathrm{Na}$ análise dos componentes principais e considerando-se a importância relativa da ordem dos componentes principais, apenas os dois primeiros componentes foram considerados, sendo que o primeiro explica $66,36 \%$ da variação total e o segundo explica $15,41 \%$ da variação total. Os dois primeiros componentes principais absorveram $81,77 \%$ da variância total das variáveis originais.

As propriedades químicas do solo que propiciaram os maiores índices de correlação com o segundo componente principal $(r>0,60)$ foram magnésio, soma de bases trocáveis, cálcio e $\mathrm{pH}$ em água. Os escores obtidos na análise discriminante dos componentes principais estão representados na figura 2 e a distribuição dos sítios de ocorrência da erva-baleeira é representada por pontos identificados por símbolos. Considerando a proximidade dos pontos, que significa semelhança entre os valores das propriedades químicas do solo para cada agrupamento, foi possível identificar quatro grupos de solos com características químicas próximas entre si. Em cada grupo formado, foram calculadas as média aritméticas dos sítios de ocorrência para identificar as variáveis que melhor caracterizam cada grupo (Tabela 2).

Os solos com maior acidez, teores de alumínio, baixa saturação por bases e alta saturação 


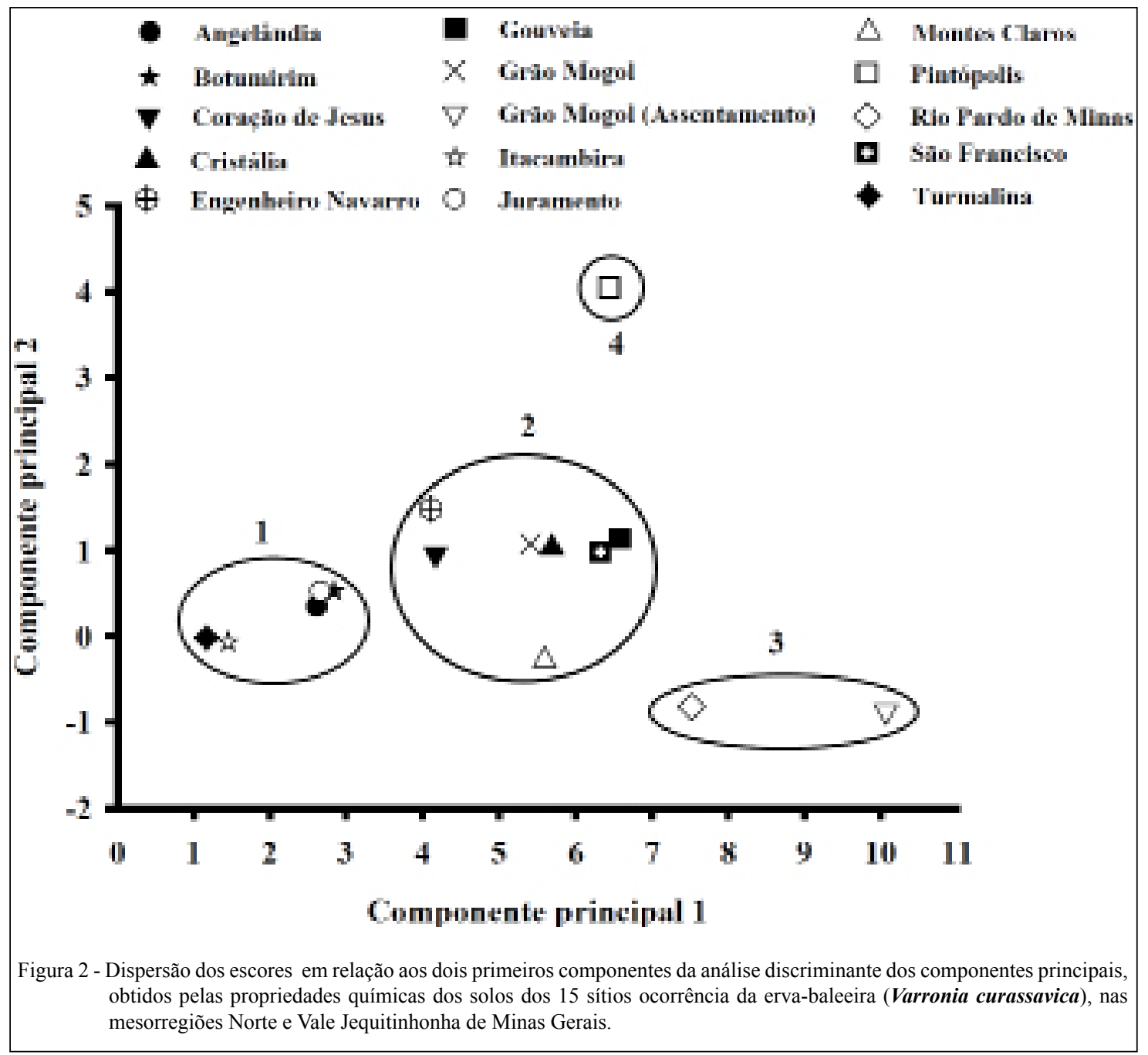

por alumínio foram observados no grupo 1 (RLd: Neossolo Litólico Distrófico - Botumirim, Itacambira e Juramento; LVAd: Latossolo Vermelho-Amarelo Distrófico - Angelândia; PVvd: Argissolo Vermelho Ta Distrófico - Turmalina). Os valores obtidos no presente estudo para as propriedades químicas dos solos estão próximos aos observados em solos sob cerrado, por SOUZA et al. (2006).

No grupo 2, quatro dos sete sítios de ocorrência apresentaram solos eutróficos, ou seja, com saturação por bases superiores a $50 \%$ (LVe: Latossolo Vermelho Eutrófico - Coração de Jesus; LVAe: Latossolo Vermelho-Amarelo Eutrófico - Engenheiro Navarro; PAe: Argissolo Amarelo Eutrófico- São Francisco). Os solos que não foram classificados como eutróficos no grupo 2 ( $\mathrm{PVvd}$ - Grão Mogol e Montes Claros; PVd: Argissolo Vermelho Distrófico - Cristália) apresentaram a atividade da fração argila considerada alta $\left(27 \mathrm{cmol}_{\mathrm{c}} \mathrm{kg}^{-1}\right.$ de argila) .
Estes aspectos podem ter influenciado a elevada retenção de potássio (Tabela 2), apresentando valores considerados de médio a bom (CFSEMG, 1999).

O grupo 3, representado pelos sítios de ocorrência Grão Mogol - Assentamento Americana (RLe: Neossolo Litólico Eutrófico) e Rio Pardo de Minas (CXve: Cambissolo Háplico Ta Eutrófico), apresentou valores mais elevados de $\mathrm{pH}$, potássio, cálcio, magnésio e soma de bases trocáveis, e os menores teores de alumínio, propriedades químicas típicas de solos eutróficos.

O solo coletado em Pintópolis (CXve) foi o único representante do grupo 4 (Figura 2), por apresentar propriedades químicas contrastantes aos demais (Tabela 2). Ressalta-se que o teor de fósforo obtido para este solo foi superior aos demais, mesmo sendo considerado baixo, segundo a CFSEMG (1999). O maior teor de fósforo disponível, provavelmente esteja relacionado ao baixo teor de 
Tabela 2 - Caracterização dos grupos formados pelas propriedades químicas (pH em água, fósforo, potássio, cálcio, magnésio, alumínio, soma de bases trocáveis, índice de saturação de alumínio, índice de saturação de bases) dos solos dos 15 sítios de ocorrência da erva-baleeira (Varronia curassavica) nas mesorregiões Norte e Vale Jequitinhonha de Minas Gerais (média \pm erro padrão).

\begin{tabular}{|c|c|c|c|c|c|}
\hline \multirow{2}{*}{ Propriedades químicas } & \multicolumn{4}{|c|}{$\begin{array}{l}- \\
\end{array}$} & \multirow{2}{*}{ Média } \\
\hline & 1 & 2 & 3 & 4 & \\
\hline $\mathrm{pH}^{1}$ & $4,80 \pm 0,34$ & $5,52 \pm 0,42$ & $6,20 \pm 0,28$ & 5,9 & $5,40 \pm 0,60$ \\
\hline $\mathrm{P}^{2}\left(\mathrm{mg} \mathrm{kg}^{-1}\right)$ & $1,57 \pm 0,91$ & $1,23 \pm 1,02$ & $0,93 \pm 0,30$ & 13,94 & $2,15 \pm 3,37$ \\
\hline $\mathrm{K}^{2}\left(\mathrm{mg} \mathrm{kg}^{-1}\right)$ & $43,60 \pm 7,05$ & $72,83 \pm 34,68$ & $360,00 \pm 115,96$ & 61 & $102,57 \pm 116,88$ \\
\hline $\mathrm{Ca}^{2+}\left(\mathrm{cmolc} \mathrm{dm}{ }^{-3}\right)$ & $0,52 \pm 0,26$ & $1,80 \pm 0,87$ & $3,60 \pm 0,42$ & 1,7 & $1,61 \pm 1,17$ \\
\hline $\mathrm{Mg}^{2+}\left(\mathrm{cmolc} \mathrm{dm}^{-3}\right)$ & $0,26 \pm 0,11$ & $0,78 \pm 0,31$ & $1,65 \pm 0,35$ & 0,9 & $0,73 \pm 0,51$ \\
\hline $\mathrm{Al}^{3+}\left(\mathrm{cmolc} \mathrm{dm}^{-3}\right)$ & $1,26 \pm 0,30$ & $0,39 \pm 0,33$ & 0 & 0 & $0,60 \pm 0,57$ \\
\hline $\mathrm{SB}^{3}\left(\mathrm{cmolc} \mathrm{dm}^{-3}\right)$ & $0,89 \pm 0,41$ & $2,74 \pm 1,20$ & $6,17 \pm 1,07$ & 2,76 & $2,58 \pm 1,90$ \\
\hline $\mathrm{m}^{4}(\%)$ & $59,80 \pm 15,45$ & $13,28 \pm 8,60$ & $3,52 \pm 4,98$ & 0 & $26,60 \pm 26,66$ \\
\hline$V^{5}(\%)$ & $17,40 \pm 10,74$ & $53,14 \pm 10,40$ & $79,00 \pm 2,82$ & 65 & $40,76 \pm 24,35$ \\
\hline $\mathrm{N}^{\circ}$ de sítios & 5 & 7 & 2 & 1 & \\
\hline
\end{tabular}

${ }^{1} \mathrm{pH}$ em água; ${ }^{2}$ Extrator Mehlich $1 ;{ }^{3}$ Soma de bases trocáveis; ${ }^{4}$ Índice de saturação de alumínio. ${ }^{5}$ Índice de saturação de bases; ${ }^{6}$ med \pm desv: mé número de sitio que ocorreram no grupo \pm desvio padrão.

argila $\left(120 \mathrm{~g} \mathrm{~kg}^{-1}\right)$, o que confere baixa capacidade de adsorção do fosfato nas superfície, aumento no teor de fósforo remanescente (P-rem) e índice de tampão de fosfato, segundo SOUZA et al. (2006).

\section{CONCLUSÃO}

A erva-baleeira não apresentou condições ecogeográficas e edafoclimáticas específicas para a sua ocorrência nas mesorregiões Norte e Vale Jequitinhonha de Minas Gerais.

\section{AGRADECIMENTOS}

À Coordenação de Aperfeiçoamento de Pessoal de Nível Superior (Capes), pela concessão de bolsa do Programa Nacional de Pós Doutorado - PNPD (AUXPE-PNPD 2877/2010) e pelo auxílio financeiro. Ao Programa Institucional de Bolsas de Iniciação Científica da Fundação de Amparo à Pesquisa do estado de Minas Gerais (FAPEMIG) e ao Programa de Educação Tutorial da Secretaria de Educação Superior (PET-SESu) pela concessão de bolsa dos estudantes, V.B. Pinto e T.B. Queiroz, respectivamente.

\section{REFERÊNCIAS}

BARATA, L.E.S. Empirismo e ciência: fonte de novos fitomedicamentos. Ciência e Cultura, v.57, p.4-5, 2005. Disponível em: $<\mathrm{http}: / /$ cienciaecultura.bvs.br/scielo.php?script=sci_arttext\&p id=S0009-67252005000400002>. Acesso em: 04 nov. 2012.

COMISSÃO DE FERTILIDADE DO SOLO DO ESTADO DE MINAS GERAIS (CFSEMG). Recomendações para o uso de corretivos e fertilizantes em Minas Gerais - 5.aprox. Viçosa, MG, 1999. 359p.

CRUZ, C.D. Programa genes: biometria. Viçosa (MG): UFV, 2006. 382p.
CRUZ, C.D.; REGAZZI, A.J. Modelos biométricos aplicados ao melhoramento genético. Viçosa: UFV, 1994. 390p.

EMBRAPA. Centro Nacional de Pesquisa de Solos. Manual de métodos de análises de solo. 2.ed. Rio de Janeiro, 1997. 212p.

FERNANDES, E.S. et al. Anti-inflammatory effects of compounds alpha-humulene and (-)-trans-caryophyllene isolated from the essential oil of Cordia verbenacea. European Journal of Pharmacology, v.569, p.228-236, 2007.

GANDOLFO, E.S.; HANAZAKI, N. Etnobotânica e urbanização: conhecimento e utilização de plantas de restinga pela comunidade nativa do distrito do Campeche (Florianópolis, SC). Acta Botanica Brasilica, v.25, p.168-177, 2011. Disponível em: <http://www. scielo.br/pdf/abb/v25n1/20.pdf $>$. Acesso em: 10 jun. 2013. doi:10.1590/S0102-33062011000100020.

GASTAUER, M. et al. Floristic composition, species richness and diversity of campo rupestre vegetation from the Itacolomi State Park, Minas Gerais, Brazil. Environment and Natural Resources Research, v.2, p.115-130, 2012. Disponível em: $<$ http://www. ccsenet.org/journal/index.php/enrr/article/view/20125/13670>. Acesso em: 10 jun. 2013. doi: 10.5539/enrr.v2n3p115.

IBGE (INSTITUTO BRASILEIRO DE GEOGRAFIA E ESTATÍSTICA). Mapas interativos. Disponível em: <http:// mapas.ibge.gov.br/tematicos>. Acesso em: 10 ago. 2012.

LOURENZANI, A.E.B.S. et al. Barreiras e oportunidades na comercialização de plantas medicinais provenientes da agricultura familiar. Informações Econômicas, v.34, p.15-25, 2004. Disponível em: <http://www.iea.sp.gov.br/OUT/publicacoes/pdf/ tec2-0304.pdf>. Acesso em: 18 abr. 2011.

MEDEIROS, R. et al. Effect of two active compounds obtained from the essential oil of Cordia verbenacea on the acute inflammatory responses elicited by LPS in the rat paw. British Journal of Pharmacology, v.151, p.618-627, 2007. Disponível em: <http:/www.ncbi.nlm.nih.gov/pmc/articles/PMC2013990/ pdf/0707270a.pdf>. Acesso em: 13 jan. 2011. doi: 10.1038/ sj.bjp. 0707270 
MILLER, J.S.; GOTTSCHLING, M. Generic classification in the Cordiaceae (Boraginales): resurrection of the genus Varronia $\mathrm{P}$. Br. Táxon, v.56, p.163-169, 2007.

MONTANARI JUNIOR, I. Variabilidade genética em uma população de Cordia verbenacea DC. para características agronômicas e fitoquímicas. 2011. 77f. Tese (Doutorado em Agronomia-Horticultura) - Curso de Pós-graduação da Faculdade de Ciências Agronômicas da Universidade Estadual Paulista Campus de Botucatu, SP.

RODAL, M.J.R.; NASCIMENTO, L.M. Levantamento florístico da floresta serrana da Reserva Biológica de Serra Negra, microrregião de Itaparica, Pernambuco, Brasil. Acta Botanica Brasilica, v.16, p.481-500, 2002. Disponível em: <http://www.scielo.br/pdf/abb/v16n4/a09v16n4.pdf>. Acesso em: 09 jun. 2013.

SÁNCHEZ, J.E. Cordia subgénero Varronia (Boraginaceae) Flora de Colombia, v.14, p.1-176, 1995. Disponível em: <http:// www.ciencias.unal.edu.co/unciencias/data-file/user_16/file/ floracol/fdc014.pdf>. Acesso em: 02 fev. 2011.

SANTOS, H.G. et al. (Ed.). Sistema brasileiro de classificação de solos. 2.ed. Rio de Janeiro: Embrapa, 2006. 316p.

SOUZA, R.F. et al. Calagem e adubação orgânica: influência na adsorção de fósforo em solos. Revista Brasileira de Ciência do Solo, v.30, p.975-983, 2006. Disponível em: <http://www.scielo. br/scielo.php?pid $=$ S0100-06832006000600007\& script $=$ sci arttext>. Acesso em: 24 jun. 2013. doi: 10.1590/S010006832006000600007

VAZ, A.P.A. et al. Biomassa e composição química de genótipos melhorados de espécies medicinais cultivadas em quatro municípios paulistas. Pesquisa Agropecuária Brasileira, v.41, p.869-872, 2006. Disponível em: <http://www.scielo. $\mathrm{br} / \mathrm{scielo.php}$ ?pid $=\mathrm{S} 0100-204 \mathrm{X} 2006000500021 \& \mathrm{script}=\mathrm{sci}$ arttext $>$. Acesso em: 08 mar. 2011. doi: 10.1590/S0100204X2006000500021. 